\title{
OCCUPATIONAL STRESS IN THE SOUTH AFRICAN POLICE SERVICE
}

\author{
J PIENAAR \\ S ROTHMANN \\ bpksr@puknet.puk.ac.za \\ WorkWell: Research Unit for People, Policy and Performance \\ North-West University
}

\begin{abstract}
Policing has been described as a stressful occupation. The objectives of this study were to develop and validate a measure that could be used by the South African Police Service (SAPS) to identify the frequency and intensity of occupational stressors and to assess the differences between the stressors for race, rank and gender groups. A crosssectional survey design was used. Stratified random samples $(N=2145)$ were taken of police members of nine provinces in South Africa. The Police Stress Inventory was developed as a measuring instrument. Three internally consistent factors were extracted through principal component analysis with a direct oblimin rotation. These factors were labelled Job Demands, Lack of Support and Crime-related Stressors. The most important stressors identified were other officers not doing their job, inadequate or poor quality equipment, inadequate salaries, and seeing criminals go free. Analysis of variance showed differences in stressors for rank, race and gender groups.
\end{abstract}

Key words

Stress, police, job demands, lack of support, crime-related stress

If one considers the socio-economic and political turmoil of the past 30 years, and the changes resulting from the dissolution of apartheid, police work is probably particularly stressful in South Africa (Gulle, Tredoux \& Foster, 1998). The South African Police Service (SAPS) has also undergone tremendous transformation since the first democratic elections in 1994. Transformation from a police force to a police service is taking place, the rank structure was changed, and an affirmative action policy was implemented (Van der Walt, 2002).

Anshel (2000) highlighted three underlying postulates in stress research with police officers. Firstly, extreme or unusual external stimuli that are perceived as threatening will be stressful and cause significant changes in psychological, physiological and behavioural responses. The second stress postulate is that the failure to cope effectively with short-term sudden stress leads to long-term, chronic stress, which might in turn inhibit the body's immune system, leading to an array of medical illnesses and diseases. Lastly, sources of police stress that are ongoing and long-term will result in burnout, reduced motivation, poor performance, and eventual dropout from the police profession (Violanti \& Aron, 1993).

Occupational stress has been related to heart disease, hypertension, upper respiratory tract infections, peptic ulcers, reduced immunity, migraines, alcoholism, depression, suicidal tendencies, anxiety, as well as other mental disorders (Lord, Gray \& Pond, 1991; Muntaner, Tien, Eaton \& Garrison, 1991). Within organisations, these effects translate into decreased performance and motivation, increased health care costs, disability payments, sick leave, absenteeism and turnover (Aldana, Sutton, Jacobson \& Quirk, 1996; Slate, Johnson \& Wells, 2000). Increased rates of illness, post-traumatic stress, medical boarding, burnout, alcohol abuse and suicides, as well as decreased levels of job satisfaction and job performance, as compared to norms for the general population, are reported in research with police members (Anshel, 2000; Nel \& Burgers, 1998; Nel, 1994; Rothmann \& Agathagelou, 2000; Rothmann \& Strijdom, 2002).

Since policing is generally accepted as being a highly stressful occupation, it presents an appealing context for the study of the effects of work stress (Anshel, 2000). Besides being a organisation with problems of hierarchy and administrative ineffectiveness, police organisations present a further unique challenge. This challenge comes in the form of potentially traumatic experiences, such as life-threatening physical assault or witnessing disturbing images of death (Stephens \& Long,
2000). Therefore, it is necessary to identify the occupational stressors of police members in South Africa. This can only be done if a valid and reliable measuring instrument of occupational stress is available.

Currently, no reliable and valid measures of occupational stress exist in South Africa that could be used to diagnose the frequency and intensity of stressors in the police service. A reliable and valid measure of stress could be an important instrument for the early identification and successful treatment of stress within the police service. Discovering which stressors are most pertinent to police officers in South Africa could lead to these stressors being addressed during selection, stress management workshops, and organisational development interventions.

The objective of this study was to develop and validate a stress measure specific to the policing environment, by focusing on typical stressors that have been identified in previous research, as well as unique stressors in the South African context. The second objective was to compare the occupational stressors for different race, rank and gender groups.

\section{Occupational stress}

The Spielberger State-Trait (STP) model of occupational stress (Spielberger, Vagg, \& Wasala, 2003) conceptualizes stress as a complex process that consists of three major components, namely sources of stress that are encountered in the work environment, the perception and appraisal of a particular stressor by an employee, and the emotional reactions that are evoked when a stressor is appraised as threatening.

The STP model of occupational stress focuses on the perceived severity and frequency of occurrence of two major categories of stressors, namely job pressures and lack of support (Spielberger et al., 2003). The STP model recognizes the importance of individual differences in personality traits in determining how workplace stressors are perceived and appraised. Occupational stress is defined as the mind-body arousal resulting from physical and/or psychological job demands. The appraisal of a stressor as threatening leads to anxiety and anger and the associated activation of the autonomic nervous system. If severe and persistent, the resulting physical and psychological strain may cause adverse behavioural consequences (Spielberger et al., 2003). Employees evaluate their work environment in terms of the severity and 
frequency of occurrence of specific job demands and pressure and the level of support provided by other employees (supervisors and co-workers), as well as organisational features (policies and procedures). Failing to take the frequency of occurrence of a particular stressor into account may contribute to overestimating the effects of highly stressful situations that rarely occur, while underestimating the effects of moderately stressful events that are frequently experienced.

In line with the STP model, two broad categories of occupational stressors in policing have been identified (Alexander, Walker, Innes \& Irving, 1993; Biggam, Power, MacDonald, Carcary \& Moodie, 1997; Brown \& Campbell, 1990, 1994). The first category to present a significant source of stress is the organisational aspects of police work, such as a lack of confidence in management, lack of internal communication and continuous organisational change. Secondly, the nature of police work, such as physical threat, force, exposure to danger, facing the unknown and shift work come into play. The most prominent of these has been identified as the organisational factor (Crank \& Caldero, 1991; Crowe \& Stradling, 1993; Evans \& Coman, 1993; Hart, Wearing \& Headey, 1995; Kop \& Euwema, 2001). Factor analytic studies of police stress have recovered different numbers of factors eight (Hart et al., 1995), five (Crowe \& Stradling, 1993) and three factors (Brown, Fielding \& Grover, 1999; Mitchell, Cowan $\&$ Hamilton, 1998) have been reported.

Gulle et al. (1998) showed that in comparison to American stressors, which were all inherent in the nature of the job, South African police stressors were more organisationally oriented. Koortzen (1996, p. 62) indicated that the three most prominent individual police stressors in a South African sample were a lack of supervisory and management skills, inappropriate sentences handed down by the courts and emotional detachment from the family. In more recent work, Peltzer (2001) found duty-related violent injury (i.e. shooting), pursuit of an armed suspect and response to a scene involving the death of a child as the three most stressful incidents relating to emotional intensity in a South African sample.

Statistics in August 2005 showed that police units against family violence, child abuse and sexual offences had 254 vacancies (20\% of total number of jobs) (Basson, 2005). The average number of criminal cases managed by each detective vary from 32 (Northern Cape) to 52 (Eastern Cape), with a national average of 43 . A rule of thumb is that each detective should not investigate more than 18 cases. A total of 43007 criminal cases are investigated by a total number of 1008 detectives. Therefore, police members (and specifically detectives) experience high job demands.

\section{Occupational stress and biographical variables}

It is apparent that stress is not experienced uniformly by police members, but varies from one individual to another (Violanti \& Aron, 1995). Studies have provided evidence that individual personality traits, for example, locus of control and type-A personality, play substantial roles in occupational stress (Cooper, Kirkcaldy \& Brown, 1994; Davey, 1994). However, reported studies of occupational stress, concerned with biographical differences, such as position and years of service, do not appear to have been as fruitful. For example, after conducting a meta-analysis of studies investigating the relationship between gender and occupational stress, Martocchio and O'Leary (1989) concluded that there were no differences in experienced stress between males and females. It may be that there is virtually no variation in occupational stress among biographically differentiated groups of police members. However, such homogeneity, particularly in a large police organisation, would appear unlikely. Moreover, some differences have been reported in a small number of studies (Brown \& Campbell, 1990; Brown, Cooper \& Kirkcaldy, 1996; Kaufmann \& Beehr, 1989).
This study focuses on three biographical variables, namely rank, gender and race. International studies showed that police officers report varying amounts of work stressors based upon rank (Brown \& Campbell, 1990; Brown, et al., 1996; Kaufmann \& Beehr, 1989), race and ethnicity (Violanti \& Aron, 1995), and gender (Wexler \& Logan, 1983). Cooper and Bramwell (1992) also showed potential sources of stress to vary between different subcultures and status groups within the same organisation; while Terry and Calan (1997) indicated that those higher in the organisational hierarchy experience higher levels of perceived stress.

\section{RESEARCH DESIGN}

\section{Research approach}

A cross-sectional survey design was used to achieve the research objectives. This design allows for the description of the population at a specific point in time, and is also suited to the development and validation of questionnaires (Shaughnessy \& Zechmeister, 1997).

\section{Participants}

Random samples $(N=2145)$ were taken from police stations in eight South African provinces. Stations were divided into small (fewer than 25 staff members), medium (25-100 staff members) and large (more than 100 staff members). All police members at randomly identified small and medium stations in each of the provinces were asked to complete the questionnaire. At the large stations, stratified random samples were taken according to gender and race. Table 1 presents some of the characteristics of the participants.

TABLE 1

Characters of THE Participants $(N=2145)$

\begin{tabular}{llc}
\hline Item & Category & Percentage \\
\hline Race & White & 37,19 \\
& Black & 42,05 \\
& Coloured & 15,80 \\
& Indian & 4,96 \\
Rank & Constable & 7,42 \\
& Sergeant & 20,90 \\
& Inspector & 50,08 \\
& Captain & 18,48 \\
Size of Station & Superintendent & 2,37 \\
& Senior superintendent & 0,76 \\
& Small & 31,48 \\
Gender & Medium & 38,07 \\
& Large & 30,45 \\
& Male & 79,92 \\
& Female & 20,08 \\
\hline
\end{tabular}

Table 1 shows that nearly half the sample was made up of black members $(42,05 \%)$. Mostly inspectors were included (50,08\%). Roughly equal numbers of officers in small, medium and large stations were included. The sample is predominantly made up of males. More than half the sample $(56,16 \%)$ had Grade 12 schooling, equal to 12 years of formal schooling. The mean age of the participants was 34,75 ( $S D=6,34)$. Furthermore, the mean number of years of participants in the SAPS was 13,02 years (SD $=6,22$ ). Furthermore, participants have been in their positions for an average of 4,29 years ( $S D=3,33$ ).

\section{Measuring instruments}

The Police Stress Inventory (PSI) was developed for purposes of this study. The PSI consists of 88 items. A number of studies have been published regarding stressors specific to the policing 
environment (Anon, 1986; Bartol, Bergen, Volckens \& Knoras, 1992; Biggam et al., 1997; Brown \& Campbell, 1990; Brown \& Fielding, 1993; Brown et al., 1996; Crank \& Caldero, 1991; Kirkcaldy, Cooper \& Ruffalo, 1995; Koortzen, 1996; Kop \& Euwema, 2001; Kop, Euwema \& Schaufeli, 1999; Loo, 1984; Patterson, 1992; Terry, 1981; Violanti \& Aron, 1994; Wexler \& Logan, 1983; White, Lawrence, Biggerstaff \& Grubb, 1985). These sources were used in the construction of the current instrument. In line with previous research (Biggam et al., 1997; Spielberger et al., 2003; Thomas, 1988), this study addressed both the severity and frequency of stressors. Firstly, participants rated each of 44 items regarding the intensity of stress on a 9-point scale. Secondly, the frequency part of the questionnaire asked how many times in the last six months the source of stress had been experienced.

A questionnaire was developed to gather information about the demographic characteristics of the participants. This questionnaire gave participants the option of supplying their name and service number. Other information that was gathered included: province, age, gender, years of service, years in current position, educational qualifications, marital status, and presence of medical conditions.

\section{Statistical analysis}

The statistical analysis was carried out with the help of the SPSS program (SPSS Inc., 2003). First, a simple principal components analysis was conducted on the 44 intensity items of the PSI for a sample of 2145 police officers. The eigenvalues and scree plot were studied to determine the number of factors. Second, a principal components analysis with a direct Oblimin rotation was conducted if factors were related, and a principal component analysis with a Varimax rotation was used if the obtained factors were not related (Tabachnick \& Fidell, 2001). Cronbach alpha coefficients were used to assess the internal consistency of the PSI (Clark \& Watson, 1995)

Multivariate analysis of variance (MANOVA) was used to determine the significance of differences between occupational stress of race, rank and gender groups. MANOVA tests whether mean differences amongst groups on a combination of dependent variables are likely to have occurred by chance (Tabachnick, \& Fidell, 2001). In MANOVA, a new dependent variable, which maximizes group differences, is created from the set of dependent variables. One-way analysis is then performed on the newly created dependent variable. Wilk's Lambda was used to test the significance of the effects. When an effect was significant in MANOVA, ANOVA was used to discover which dependent variables were affected. Because multiple ANOVAs were used, a Bonferroni-type adjustment was made for inflated Type 1 error.

\section{RESULTS}

A simple principal component analysis was carried out on the PSI. Six components, which explained $58,25 \%$ of the total variance, had eigenvalues larger than one. However, the scree plot showed that three factors could be extracted. These three factors explained $52,64 \%$ of the total variance. Principal component analysis with a direct oblimin rotation showed interfactor correlations between Factor 1 and Factor $2(r=0,38)$, and between Factor 2 and Factor $3(r=0,41)$. The pattern matrix of the PSI is reported in Table 2.

Items loading on the first factor relate to job demands in the policing environment. They deal with, amongst other things, personal time, personal responsibility, the unpleasant nature of administrative tasks, and the time spent at work. The second factor consists of stressors mostly found only in a police environment, including death (of either a civilian or fellow officer), having to deal with violent or potentially violent situations and having to handle conflict. The third factor seems to address a lack of support (from colleagues, supervisors and the organisation). The items that loaded on this factor are related to the equipment being used, the opportunities for advancement, poor pay, a lack of cooperation and motivation among officers, and a lack of staff.

TABLE 2

Principal components factor analysis With a diRect OBLIMIN ROTATION ON THE PSI

\begin{tabular}{|c|c|c|c|}
\hline & \multicolumn{3}{|c|}{ Component } \\
\hline & 1 & 2 & 3 \\
\hline Frequent changes from boring to demanding activities & 0,69 & 0,04 & $-0,08$ \\
\hline Assignment of increased responsibility & 0,69 & $-0,14$ & $-0,13$ \\
\hline Shift work & 0,66 & 0,06 & 0,10 \\
\hline Meeting deadlines & 0,65 & $-0,03$ & $-0,14$ \\
\hline Assignment of new or unfamiliar duties & 0,63 & $-0,05$ & $-0,08$ \\
\hline Having to go to court & 0,62 & 0,30 & 0,24 \\
\hline Working overtime & 0,60 & $-0,16$ & $-0,06$ \\
\hline Insufficient personal time (e.g. coffee breaks, lunch) & 0,59 & 0,00 & $-0,14$ \\
\hline Dealing with crisis situations & 0,59 & 0,02 & $-0,18$ \\
\hline Making critical on-the-spot decisions & 0,56 & 0,08 & $-0,23$ \\
\hline Too much supervision & 0,54 & 0,14 & $-0,03$ \\
\hline Attending to incidences of domestic violence & 0,54 & 0,36 & 0,07 \\
\hline Excessive paperwork & 0,53 & $-0,07$ & $-0,29$ \\
\hline Performing tasks not in job description & 0,47 & $-0,12$ & $-0,35$ \\
\hline Covering work for another employee & 0,43 & 0,03 & $-0,35$ \\
\hline Noisy work area & 0,43 & 0,24 & $-0,12$ \\
\hline Frequent interruptions & 0,42 & 0,11 & $-0,33$ \\
\hline $\begin{array}{l}\text { Reorganisation and transformation within } \\
\text { the organisation }\end{array}$ & 0,42 & 0,12 & $-0,22$ \\
\hline Periods of inactivity & 0,37 & 0,04 & $-0,28$ \\
\hline A fellow officer killed in the line of duty & $-0,28$ & 0,82 & $-0,28$ \\
\hline Killing someone in the line of duty & $-0,16$ & 0,80 & $-0,16$ \\
\hline A forced arrest or being physically attacked & 0,16 & 0,70 & $-0,12$ \\
\hline Having to handle a large crowd/mass demonstration & 0,27 & 0,67 & 0,01 \\
\hline Racial conflict & $-0,02$ & 0,61 & $-0,29$ \\
\hline Delivering a death message or bad news to someone & 0,32 & 0,57 & 0,07 \\
\hline Having to deal with the media & 0,45 & 0,50 & 0,14 \\
\hline $\begin{array}{l}\text { Seeing criminals go free (for example because of lack } \\
\text { of evidence, court leniency) }\end{array}$ & $-0,08$ & 0,50 & $-0,40$ \\
\hline Inadequate or poor quality equipment & $-0,04$ & 0,07 & $-0,74$ \\
\hline Insufficient personnel to handle an assignment & 0,07 & 0,02 & $-0,73$ \\
\hline Lack of opportunity for advancement & $-0,09$ & 0,03 & $-0,71$ \\
\hline Lack of recognition for good work & 0,07 & $-0,04$ & $-0,71$ \\
\hline Inadequate support by supervisor & 0,01 & $-0,02$ & $-0,69$ \\
\hline Fellow workers not doing their job & $-0,03$ & 0,12 & $-0,68$ \\
\hline Inadequate salary & $-0,04$ & 0,09 & $-0,64$ \\
\hline $\begin{array}{l}\text { Experiencing negative attitudes toward the } \\
\text { organisation }\end{array}$ & 0,14 & 0,01 & $-0,63$ \\
\hline Poor or inadequate supervision & 0,15 & 0,05 & $-0,60$ \\
\hline Poorly motivated co-workers & 0,20 & 0,08 & $-0,58$ \\
\hline Staff shortages & 0,09 & 0,12 & $-0,54$ \\
\hline Competition for advancement & 0,26 & 0,01 & $-0,48$ \\
\hline Difficulty getting along with supervisor & 0,19 & 0,04 & $-0,48$ \\
\hline Lack of participation in policy-making decisions & 0,27 & 0,08 & $-0,47$ \\
\hline Assignment of disagreeable duties & 0,31 & 0,06 & $-0,33$ \\
\hline Conflicts with other departments & 0,29 & 0,22 & $-0,33$ \\
\hline Personal insult from customer/consumer/colleague & 0,31 & 0,26 & $-0,32$ \\
\hline
\end{tabular}


The descriptive statistics and alpha coefficients for the extracted PSI factors are reported in Table 3.

TABLE 3

DESCRIPTIVE STATISTICS AND ALPHA COEFFICIENTS OF THE PSI FACTORS

\begin{tabular}{llccccc}
\hline Item & & Mean & SD & Skewness & Kurtosis & $\alpha$ \\
\hline Job Demands & Intensity & 90,23 & 28,29 & $-0,17$ & 0,05 & 0,92 \\
& Frequency & 77,73 & 35,63 & 0,01 & $-0,18$ & 0,92 \\
& Intensity & 42,14 & 16,10 & $-0,32$ & $-0,72$ & 0,93 \\
$\begin{array}{l}\text { Crime-related } \\
\text { Stressors }\end{array}$ & & & & & \\
& Frequency & 21,24 & 17,28 & 0,95 & 0,37 & 0,88 \\
& Intensity & 93,74 & 26,81 & $-0,48$ & 0,20 & 0,89 \\
Lack of Support & Frequency & 71,48 & 32,21 & $-0,09$ & $-0,38$ & 0,92 \\
& & & & & & \\
\hline
\end{tabular}

Table 3 shows that the alpha coefficients of the three extracted factors of the PSI are highly acceptable compared to the guideline of 0,70 (Nunnally \& Bernstein, 1994). The values can be considered high and thus explain a large proportion of the variance in the different scales (Clark \& Watson, 1995).

The intensity and frequency of the stressors as measured by the PSI are reported in Table 4.

TABLE 4

DESCRIPTIVE STATISTICS OF STRESSOR ITENSITY AND FREQUENCY ITEMS FOR POLICE OFFICERS

\begin{tabular}{|c|c|c|c|c|c|}
\hline \multirow[t]{2}{*}{ Item } & \multicolumn{2}{|c|}{ Intensity } & \multicolumn{2}{|c|}{ Frequency } & \multirow[t]{2}{*}{ Severity } \\
\hline & Mean & SD & Mean & SD & \\
\hline $\begin{array}{l}\text { Frequent changes from boring to } \\
\text { demanding activities }\end{array}$ & 4,52 & 2,30 & 3,98 & 3,10 & 17,99 \\
\hline Assignment of increased responsibility & 4,93 & 2,32 & 4,56 & 3,04 & 22,48 \\
\hline Shiftwork & 4,20 & 2,62 & 3,43 & 3,38 & 14,41 \\
\hline Meeting deadlines & 4,82 & 2,40 & 4,54 & 3,22 & 21,88 \\
\hline Assignment of new or unfamiliar duties & 4,60 & 2,27 & 3,69 & 3,00 & 16,97 \\
\hline Having to go to court & 4,36 & 2,58 & 3,75 & 3,22 & 16,35 \\
\hline Working overtime & 4,58 & 2,52 & 4,51 & 3,28 & 20,65 \\
\hline $\begin{array}{l}\text { Insufficient personal time (e.g. coffee } \\
\text { breaks, lunch) }\end{array}$ & 4,54 & 2,60 & 4,05 & 3,34 & 13,39 \\
\hline Dealing with crisis situations & 5,09 & 2,34 & 4,46 & 3,10 & 22,70 \\
\hline Making critical on-the-spot decisions & 4,70 & 2,29 & 4,08 & 3,08 & 19,18 \\
\hline Too much supervision & 4,52 & 2,58 & 3,26 & 3,17 & 14,73 \\
\hline $\begin{array}{l}\text { Attending to incidences of domestic } \\
\text { violence }\end{array}$ & 4,90 & 2,55 & 3,79 & 3,26 & 18,57 \\
\hline Excessive paperwork & 5,37 & 2,50 & 5,34 & 3,23 & 28,68 \\
\hline Performing tasks not in job description & 5,07 & 2,55 & 4,92 & 3,24 & 24,94 \\
\hline Covering work for another employee & 5,23 & 2,49 & 4,74 & 3,17 & 24,79 \\
\hline Noisy work area & 4,51 & 2,58 & 3,52 & 3,27 & 15,87 \\
\hline Frequent interruptions & 5,02 & 2,45 & 4,53 & 3,24 & 18,21 \\
\hline $\begin{array}{l}\text { Reorganization and transformation } \\
\text { within the organisation }\end{array}$ & 4,84 & 2,48 & 3,63 & 3,10 & 17,57 \\
\hline Periods of inactivity & 4,63 & 2,30 & 3,11 & 2,87 & 14,39 \\
\hline A fellow officer killed in the line of duty & 6,09 & 3,05 & 2,17 & 3,06 & 18,63 \\
\hline Killing someone in the line of duty & 5,28 & 3,17 & 1,69 & 2,85 & 15,05 \\
\hline $\begin{array}{l}\text { A forced arrest or being physically } \\
\text { attacked }\end{array}$ & 5,24 & 2,67 & 2,71 & 3,00 & 14,20 \\
\hline $\begin{array}{l}\text { Having to handle a large crowd/mass } \\
\text { demonstration }\end{array}$ & 4,80 & 2,59 & 2,48 & 2,93 & 11,90 \\
\hline Racial conflict & 5,54 & 2,81 & 3,13 & 3,21 & 17,34 \\
\hline $\begin{array}{l}\text { Delivering a death message or bad } \\
\text { news to someone }\end{array}$ & 4,72 & 2,65 & 2,57 & 2,90 & 12,13 \\
\hline Having to deal with the media & 3,91 & 2,45 & 2,12 & 2,80 & 8,28 \\
\hline $\begin{array}{l}\text { Seeing criminals go free (because of } \\
\text { lack of evidence) }\end{array}$ & 6,42 & 2,62 & 4,56 & 3,43 & 29,27 \\
\hline Inadequate or poor quality equipment & 6,06 & 2,55 & 5,34 & 3,26 & 19,76 \\
\hline $\begin{array}{l}\text { Insufficient personnel to handle } \\
\text { an assignment }\end{array}$ & 5,75 & 2,48 & 5,13 & 3,26 & 29,55 \\
\hline Lack of opportunity for advancement & 5,65 & 2,54 & 4,11 & 3,27 & 23,22 \\
\hline
\end{tabular}
Inadequate support by supervisor Inadequate salary

Experiencing negative attitudes toward the organisation Poorly motivated co-workers

Staff shortages

Competition for advancement

Difficulty getting along with supervisor

Lack of participation in policymaking decisions

Assignment of disagreeable duties Conflicts with other departments

Personal insult from customer/

consumer/colleague
Lack of recognition for good work Fellow workers not doing their job

Poor or inadequate supervision

$\begin{array}{lllll}5,79 & 2,51 & 4,68 & 3,31 & 27,09 \\ 5,56 & 2,51 & 3,97 & 3,23 & 22,07 \\ 6,16 & 2,49 & 5,43 & 3,23 & 33,45 \\ 6,23 & 2,83 & 5,36 & 3,38 & 33,39 \\ 5,12 & 2,44 & 4,31 & 3,26 & 22,07 \\ & & & & \\ 5,15 & 2,53 & 3,53 & 3,15 & 18,18 \\ 5,61 & 2,49 & 5,14 & 3,23 & 28,84 \\ 6,46 & 2,59 & 5,97 & 3,28 & 38,57 \\ 5,13 & 2,36 & 3,90 & 3,17 & 20,01 \\ 4,62 & 2,53 & 3,02 & 2,98 & 13,95 \\ 5,08 & 2,39 & 3,77 & 3,14 & 19,15 \\ & & & & \\ 4,83 & 2,17 & 3,48 & 3,00 & 16,81 \\ 4,94 & 2,52 & 3,65 & 3,16 & 18,03 \\ 5,03 & 2,57 & 3,94 & 3,18 & 19,91\end{array}$

Table 4 shows that the severity (i.e. the product of intensity and frequency) was the highest for the following stressors: Seeing criminals go free (because of lack of evidence), inadequate or poor quality equipment, insufficient personnel to handle an assignment, lack of opportunity for advancement, lack of recognition for good work, fellow workers not doing their jobs, inadequate salary, experiencing negative attitudes toward the organisation, poorly motivated co-workers and excessive paperwork.

The MANOVAs of the differences between the occupational stress of race, rank and gender groups are presented in Table 5 .

TABLE 5

MANOVAS OF OCCUPATIONAL STRESSORS OF RACE, RANK AND GENDER GROUPS

\begin{tabular}{lcccccc}
\hline Variable & Value & F & df & Error df & p & $\begin{array}{c}\text { Partial } \eta^{2} \\
\text { (eta squared) }\end{array}$ \\
\hline Race & 0,83 & 21,80 & 18 & 5795,93 & 0,00 & 0,06 \\
Rank & 0,94 & 4,81 & 24 & 6877,21 & 0,00 & 0,01 \\
Gender & 0,97 & 9,22 & 6 & 2110 & 0,00 & 0,03 \\
\hline
\end{tabular}

Table 5 shows that race impacted significantly on the combined dependent-variable of Occupational stressors $(\mathrm{F}(18,5795)=$ 21,80, p < 0,01; Wilks' Lambda =0,83; partial h2=0,06). This effect was moderate ( $6 \%$ of the variance explained). Analysis of each dependent variable, using a Bonferroni adjusted alpha level of 0,025 , showed that race groups differed in terms of the intensity of Crime-related stressors $(F(3,2058)=27,54, p<0,01$, partial $\left.\eta^{2}=0,04\right)$ and Lack of support $(\mathrm{F}(3,2058)=25,88$, p < 0,01 , partial $\left.\eta^{2}=0,04\right)$, as well as the frequency of Crime-related stressors $\left(F(3,2058)=23,78, p<0,01\right.$, partial $\left.\eta^{2}=0,03\right)$ and Lack of support $\left(\mathrm{F}(3,2058)=17,90, \mathrm{p}<0,01\right.$, partial $\left.\eta^{2}=0,03\right)$. Whites and Indians (compared with blacks and Coloureds) more intensely and frequently experienced higher levels of intensity of crime-related stress and experienced stress because of a lack of support. However, whites experienced crime-related stressors less frequently than blacks.

Table 5 also shows that rank impacted significantly on the combined dependent variable Occupational stressors ( $\mathrm{F}(24$, $6877)=4,81, \mathrm{p}<0,01 ;$ Wilks' Lambda $=0,94 ;$ partial h2 $=0,01)$. This effect was small (1\% of the variance explained). Analysis of each dependent variable, using a Bonferroni adjusted alpha level of 0,002 , showed that ranks differed in terms of the intensity of Job demands $\left(F(4,1980)=4,47, p<0,01\right.$, partial $\left.\eta^{2}=0,01\right)$ and Lack of support $\left(\mathrm{F}(4,1980)=9,35, \mathrm{p}<0,01\right.$, partial $\left.\eta^{2}=0,02\right)$, as well as the frequency of Job demands $(F(4,1980)=9,61, \mathrm{p}<0,01$, partial $\left.\eta^{2}=0,02\right)$, Crime-related stressors $(F(4,1980)=5,83, p<$ 0,01 , partial $\left.\eta^{2}=0,01\right)$ and Lack of support $(F(4,1980)=10,29$, $\mathrm{p}<0,01$, partial $\eta^{2}=0,02$ ). Constables (compared with all other 
ranks) experienced lower intensity of stress regarding job demands and a lack of support. Constables (compared with other ranks) also less frequently experienced job demands, crime-related stressors and lack of support. Also, police members with a rank of superintendent or higher less frequently experienced crime-related stress than sergeants, inspectors and captains.

Lastly, Table 5 shows that gender impacted significantly on the combined dependent variable of Occupational stressors $(\mathrm{F}(6$, $2110)=9,22, p<0,01$; Wilk's Lambda $=0,97$; partial $\eta^{2}=0,03$ ). This effect was small (3\% of the variance explained). Analysis of each dependent variable, using a Bonferroni adjusted alpha level of 0,005 , showed that males and females differed in terms of the intensity of Crime-related stressors $(F(1,2116)=20,29, p<0,01$, partial $\left.\eta^{2}=0,01\right)$ as well as their Intensity $(F(1,2116)=11,89$, $\mathrm{p}<0,01$, partial $\eta^{2}=0,01$. Females (compared with males) experienced crime-related stressors less intensely and frequently.

\section{DISCUSSION}

The objectives of this study were to develop and validate a measure that could be used by the South African Police Service (SAPS) to identify the frequency and intensity of occupational stressors, and to assess the differences between the stressors for race, rank and gender groups. Three occupational stress factors were extracted, namely job demands, lack of support, and crimerelated stressors. Race, gender and rank were found to be related to occupational stress.

The factors that were extracted show some similarity to factors previously extracted in other studies of police stress (Alexander et al., 1993; Biggam et al., 1997; Brown \& Campbell, 1990, 1994; Brown et al., 1999; Mitchell et al., 1998). However, the factor structure obtained in this study supports the STP model of stress (Spielberger et al., 2003) and not a 5-factor model (Gulle et al., 1998). Factors that were extracted showed internal consistency, which point to the utility of the instrument developed in the current research.

The first factor emphasizes the demands placed on the individual in the fulfilment of his/her tasks as police officer, and thus the factor was labelled Job demands. The items loading on this factor refer to demands associated with police jobs. Specific stressors that were experienced as severe in this sample of police members, include excessive paperwork.

The second factor is a partial replication of one earlier identified (Brown et al., 1999; Mitchell et al., 1998). These items had to do with events that would only take place in the performance of a job as a police officer and was accordingly labelled Crime-related stressors. Although these seemed to be a source of acute stress, the relative infrequency with which they are experienced probably reduced their effect in the total sample. The reason for this is that stressors such as a fellow officer killed in the line of duty, or killing someone in the line of duty tend to happen infrequently, or they happen to a relatively small percentage of SAPS members. One stressor which formed part of this factor was quite severe, and that was seeing criminals go free. Probably police members perceive that they invested much effort to find criminals, but that they go free, either because of poor work by the police and/or by the legislative system.

The third factor seemingly relates to the role the organisation, supervisors and colleagues have in reducing the effects of job demands; the functional support and achievement of work goals and the stimulation of personal growth, learning and development. Accordingly, this factor was labelled Lack of support. Severe stressors in this regard included insufficient staff to handle assignments, lack of recognition for good work, fellow workers not doing their jobs, and poor remuneration. Police members' jobs will be extremely stressful if they are faced by high job demands, but they lack the resources to do their jobs properly (see Demerouti, Nachreiner, Bakker \& Schaufeli, 2001).

Race impacted significantly on the experience of occupational stress in the SAPS. Although all the race groups experienced more stress because of a lack of support (compared to the other occupational stressors), the results showed that whites and Indians (compared with blacks and Coloureds) experienced it more intensely and frequently. Support (as measured by the PSI) includes salary, promotion and recognition. The availability of these resources is to an extent affected by the implementation of employment equity in the police. It is therefore understandable that blacks would experience less stress about a lack of support than other groups. On the other hand, Coloureds did not experience more stress about a lack of support than blacks. However, it should be kept in mind that the Coloured police officers who were included in the sample were predominantly employed in the Western Cape and Northern Cape, where they were not threatened by employment equity to the same extent than Whites and Indians in other provinces.

Rank also impacted significantly on the experience of occupational stress in the police. Constables (compared with all other ranks) experienced lower intensity of stress regarding job demands and a lack of support. Constables (compared with other ranks) also less frequently experienced stress because of job demands, crime-related stressors and lack of support. Constables are not exposed to the demands and lack of support to the same extent and for such a lengthy period as other police officers. However, it should be kept in mind that constables represented only about $7 \%$ of the total sample. Therefore, these results might be influenced by sampling error. Furthermore, the fact that members with the rank of superintendent or higher less frequently experienced crime-related stress than sergeants, inspectors and captains can be explained by the fact that they are less involved with operational work. The fact that females are less operationally involved also explains why they experienced crime-related stressors less intensely and frequently.

In the total sample, stressors related to a lack of support could be regarded as severe. These include other officers' not doing their job, inadequate or poor quality equipment, inadequate salary and lack of advancement opportunities, and lack of recognition. The SAPS is also plagued by a lack of funds to fight crime in a transforming society, which is characterized by a high crime level. This may explain the stress caused by inadequate or poor quality equipment. A lack of equipment has been shown to give rise to feelings of uncertainty and frustration. In a situation already fraught with stress because of poor motivation, low pay and a legal system perceived as inadequate, feelings of ineffectiveness are exacerbated by poor quality equipment.

\section{RECOMMENDATIONS}

It is suggested that the SAPS focus on providing officers with the resources they need, both organisationally and personally. Sources of stress that should be a first priority for stress management programmes have been identified. This perhaps places the onus on government for the provision of additional funding, but such funding could contribute directly to the internal stability of the country and the economy.

This study is the first step in developing a comprehensive profile of police stress in that it identified operant stressors in the SAPS. The next step would be to study stress holistically (both work and non-work domains) and the additive and interactive effects of stressors (Cooper, Dewe \& O'Driscoll, 2001). It is further suggested that the equivalence of stress factors be studied in different racial and language groups.

The instrument that was developed in this research needs to be further refined and retested in other police samples, and 
possibly among other Southern African police forces. Illustrating concurrent validity by using it in conjunction with other measures of stress is also recommended.

\section{AUTHOR'S NOTE}

This paper is based upon work supported by the (South African) National Research Foundation under Grant number 2053344.

\section{REFERENCES}

Aldana, S.G., Sutton, L.D., Jacobson, B.H. \& Quirk, M.G. (1996). Relationships between leisure time physical activity and perceived stress. Perceptual and Motor Skills, 82, 315-321.

Alexander, D.A., Walker, L.G., Innes, G. \& Irving, B.L. (1993). Police stress at work. London: Police Foundation.

Anon. (1986). Stress in police officers - An American perspective. Servamus, November, p. 46

Anshel, M.H. (2000). A conceptual model and implications for coping with stressful events in police work. Criminal Justice and Behavior, 27, 375-400.

Bartol, C.R., Bergen, G.T., Volckens, J.S. \& Knoras, K.M. (1992). Women in small-town policing. Job performance and stress. Criminal Justice and Behavior, 19, 240-259.

Basson, A. (2005, August 4). Skoksyfers wys polisie is oorbelaai. Beeld.

Biggam, F.H., Power, K.G., MacDonald, R.R., Carcary, W.B. \& Moodie, E. (1997). Self-perceived occupational distress in a Scottish police force. Work and Stress, 11, 118-133.

Brown, J.M. \& Campbell, E.A. (1990). Sources of occupational stress in the police. Work and Stress, 4, 305-318.

Brown, J.M. \& Campbell, E.A. (1994). Stress and policing: Sources and strategies. Chichester, UK: Wiley.

Brown, J., Cooper, C. \& Kirkcaldy, B. (1996). Occupational stress among senior police officers. British Journal of Psychology, 87, $31-41$.

Brown, J. \& Fielding, J. (1993). Qualitative differences in men and women police officers' experiences of occupational stress. Work and Stress, 7, 327-340.

Brown, J., Fielding, J. \& Grover, J. (1999). Distinguishing traumatic, vicarious and routine operational stressor exposure and attendant adverse consequences in a sample of police officers. Work and Stress, 13, 312-325.

Clark, L.A. \& Watson, D. (1995). Constructing validity: Basic issues in objective scale development. Psychological Assessment, 7, 309-319.

Cooper, C.L. \& Bramwell, R. (1992). Predictive validity of the strain components of the occupational stress indicator. Stress Medicine, 8, 57-60.

Cooper, C.L., Dewe, P.J. \& O'Driscoll, M.P. (2001). Organizational stress: A review and critique of theory, research, and applications. London: Sage Publications.

Cooper, C.L., Kirkcaldy, B.D. \& Brown, J. (1994). A model of job stress and physical health: The role of individual differences. Personality and Individual Differences, 16, 653-655.

Crank, J.P. \& Caldero, M. (1991). The production of occupational stress in medium-sized police agencies: A survey of line officers in eight municipal departments. Journal of Criminal Justice, 19, 339-349.

Crowe, G. \& Stradling, S.G. (1993). Dimensions of perceived stress in a British police force. Policing and Society, 3, 137-150.

Davey, G.C.L. (1994). Trait factors and ratings of controllability as predictors of worrying about significant life stressors. Personality and Individual Differences, 16: 379-384.

Demerouti, E., Nachreiner, F., Bakker, A.B. \& Schaufeli, W.B. (2001). The job demands-resources model of burnout. Journal of Applied Psychology, 86, 499-512.

Evans, B.J. \& Coman, G.J. (1993). General versus specific measures of occupational stress: An Australian police survey. Stress Medicine, 9, 11-20.
Gulle, G., Tredoux, C. \& Foster, D. (1998). Inherent and organisational stress in the SAPS: an empirical survey in the Western Cape. South African Journal of Psychology, 28, 129-134.

Hart, P.M., Wearing, A.J. \& Headey, B. (1995). Police stress and well-being: Integrating personality, coping and daily work experiences. Journal of Occupational and Organizational Psychology, 68, 133-156.

Kaufmann, G.M. \& Beehr, T.A. (1989). Occupational stressors, individual strains, and social supports among police officers. Human Relations, 2, 185-197.

Kirkcaldy, B., Cooper, C. L. \& Ruffalo, P. (1995). Work stress and health in a sample of U.S. police. Psychological Reports, 76, 700-702.

Koortzen, P. (1996). Die dimensionaliteit van polisiestressore. Acta Criminologia, 9, 55-63.

Kop, N. \& Euwema, M.C. (2001). Occupational stress and the use of force by Dutch police officers. Criminal Justice and Behavior, 28, 631-652.

Kop, N., Euwema, M. \& Schaufeli, W. (1999). Burnout, job stress and violent behaviour among Dutch police officers. Work and Stress, 13, 326-340.

Loo, R. (1984). Occupational stress in the law enforcement profession. Canada's Mental Health, 31, 10-13.

Lord, V.B., Gray, D. O. \& Pond, S.B. (1991). The Police Stress Inventory: Does it measure stress? Journal of Criminal Justice, 19, 139-149.

Martocchio, J.J. \& O'Leary, A.M. (1989). Sex differences in occupational stress: A meta-analytic view. Journal of Applied Psychology, 74, 495-501.

Mitchell, M., Cowan, M. \& Hamilton, R. (1998). Facing violence: Assessing the training and support needs of police constables in Scotland. Edinburgh: Scottish Office Central Research Unit.

Muntaner, C., Tien, A., Eaton, W.W. \& Garrison, R. (1991). Occupational characteristics and the occurrence of psychotic disorders. Social Psychiatry and Psychiatric Epidemiology, 26, 273-280.

Nel, J. \& Burgers, T. (1998). Stress and trauma in the work environment: The South African Police Service. Unisa Psychologia, 25 (2), 17-25

Nel, J. (1994). A contextual approach to post-shooting trauma in the South African Police Service. Unpublished master's dissertation, Rand Afrikaans University, Johannesburg.

Nennally, J.C. \& Bernstein, I.H. (1994). Psychometric Theory (3rd edition). New York:McGraw-Hill.

Patterson, B.L. (1992). Job experience and perceived job stress among police, correctional, and probation/parole officers. Criminal Justice and Behavior, 19, 260-285.

Peltzer, K. (2001). Stress and traumatic symptoms among police officers at a South African police station. Acta Criminologica, $14,52-56$

Rothmann, S. \& Agathagelou, A.M. (2000). Die verband tussen lokus van beheer en werkstevredenheid by senior polisiepersoneel. Tydskrif vir Bedryfsielkunde, 26 (2), 20-26.

Rothmann, S. \& Strijdom, G. (2002). Suicide ideation in the South African Police Service in the North West Province. South African Journal of Industrial Psychology, 28 (1). 44-48.

Shaughnessy, J.J. \& Zechmeister, E.B. (1997). Research methods in psychology (4th ed.). New York, McGraw-Hill.

Slate, R.N., Johnson, W.W. \& Wells, T.L. (2000). Probation officer stress: Is there an organizational solution? Federal Probation, $64,56-59$.

Spielberger, C.D., Vagg, P.R., \& Wasala, C.F. (2003). Occupational stress: Job pressures and lack of support. In J.C. Quick \& L. E. Tetrick (Eds.), Handbook of occupational health psychology (pp. 185-200). Washington, DC, American Psychological Association.

SPSS Inc. (2003). SPSS 12.0 for Windows, Chicago, IL, Author. 
Stephens, C. \& Long, N. (2000). Communication with police supervisors and peers as a buffer to work-related traumatic stress. Journal of Organizational Behavior, 21, 407-424.

Tabachnick B.G. \& Fidell, L.S. (2001). Using multivariate statistics ( $4^{\text {th }}$ ed.). Boston, MA, Allyn \& Bacon.

Terry, D.J. \& Callan, V.J. (1997). Employee adjustment to largescale organisational change. Australian Psychologist, 32, 203-210.

Terry, W.C. III (1981). Police stress: The empirical evidence. Journal of Police Science and Administration, 9, 61-75

Thomas, R.L.T. (1988). Stress perception among select federal probation and pre-trial services officers and their supervisors. Federal Probation, 52, 48-58.
Van der Walt, J. (2002, March). Burnout: The socially acknowledged form of social distancing: A group analytical explorative study among psychologists in the South African Police Service. Paper presented at the $1^{\text {st }}$ South Africa Burnout Conference, Potchefstroom.

Violanti, J.M. \& Aron, F. (1993). Ranking police stressors. Psychological Reports, 75, 824-826.

Wexler, J.G. \& Logan, D.D. (1983). Sources of stress among women police officers. Journal of Police Science and Administration, 11, 46-53.

White, J.W., Lawrence, P.S., Biggerstaff, C. \& Grubb, T.D. (1985) Factors of stress among police officers. Criminal Justice and Behavior, 12, 111-128. 